\title{
Duplication of Ureter in the Cadaveric Dissection: A Systematic Review
}

\author{
Dr. Chaudhari Gunwant ${ }^{1}$, Dr. Chaudhari Heena ${ }^{2}$, Dr. Singel T. $C^{3}$, Dr. Sonawane Monali ${ }^{4}$
}

${ }^{1}$ Professor and Head, Department of Anatomy, Zydus Medical College and Hospital, Muvaalia, Rabdal, Gujarat 389151, India
${ }^{2}$ Assistant Professor, Department of Anatomy, Zydus Medical College and Hospital, Muvaalia, Rabdal, Gujarat 389151, India
${ }^{3}$ Professor, Department of Anatomy, Zydus Medical College and Hospital, Muvaalia, Rabdal, Gujarat 389151, India
${ }^{4}$ Associate Professor, Department of Anatomy, Zydus Medical College and Hospital, Muvaalia, Rabdal, Gujarat 389151, India

DOI: 10.36348/sijap.2020.v03i07.001

| Received: 10.07.2020 | Accepted: 22.07.2020 | Published: 26.07.2020

*Corresponding author: Dr. Sonawane Monali

Abstract

Ureteric duplication is the most common anomaly of urinary system. It may be complete, incomplete, unilateral or bilateral. In the present systematic review, we searched online databases according to PRISMA method for the availability of literature in the form of original research articles as well as case reports describing the duplication of ureter in the human cadaveric dissection for the duration from January 2011 to May 2020. We include 8 original research articles and 14 case reports in the present study. We thoroughly discuss all these articles on the basis of unilateral or bilateral; complete or incomplete duplication of ureter as well as other associated abnormalities of urogenital system. Data compilation of all these studies show higher incidence of left incomplete ureteric duplication as compared to right incomplete ureteric duplication. No such difference was found for the incidence of left and right complete ureteric duplication.

Keywords: Ureter, Duplication, Cadaver.

Copyright @ 2020: This is an open-access article distributed under the terms of the Creative Commons Attribution license which permits unrestricted use, distribution, and reproduction in any medium for non-commercial use (NonCommercial, or CC-BY-NC) provided the original author and source are credited.

\section{INTRODUCTION}

The ureters are a pair of narrow thick walled muscular tube having $25-30 \mathrm{~cm}$ length and continuous superiorly with the funnel shaped renal pelvis. Each ureter first descends slightly medially anterior to the psoas major muscle. After crossing pelvic inlet, it enters into the pelvic cavity where it curves initially laterally and then medially to open into the base of urinary bladder [1]. Duplication of ureter is the most common anomaly of urinary system. It may be complete, incomplete, unilateral or bilateral [2]. Occurrence of incomplete duplication of ureter is three times more than the complete duplication of ureter. Incidence of unilateral duplication of ureter is 1 in 125 individuals while bilateral duplication of ureter has incidence of 1 in 800 individuals [3]. Duplication of ureters can be associated with other abnormalities of kidney, renal vessels as well as urinary bladder [4]. Duplication of ureter may remain asymptomatic throughout the life. These cases of duplication of ureters are found only accidentally during routine anatomical dissection or during radiological investigative procedures $[5,6]$. Duplication of ureter may cause renal calculi, urinary tract infections, pyelonephritis, stenosis and may get injured during various abdominal surgeries [7, 8].
Collecting part of the urinary system develops from the ureteric bud and the excretory part develops from metanephric blastema. Ureteric bud develops as an outgrowth from the mesonephric ducts, penetrates the metanephric tissue and induce the metanephric blastema to form kidneys. Later the ureteric bud divides and gives rise to the ureter, renal pelvis, major and minor calyces and collecting tubules. Early divisions of the ureteric bud before penetrating the metanephric tissue give rise to bifurcated renal pelvis with incomplete duplication of ureter [9].

The aim of the present study was to conduct systematic review of literature available regarding duplication of ureter found during cadaveric dissection and critically appraise the same.

\section{MATERIALS AND METHODS Search Strategy}

Systemic search of online databases were done according to PRISMA method for availability of literature regarding duplication of ureter in the cadaveric dissection for the duration from January 2011 to May 2020 [10]. Databases included for search were PubMed, Medline, Research gate and Google scholar. In addition to all these databases, random search was 
also done for availability of suitable literature. At first all the articles were searched showing the duplication of ureter. Slowly appropriate filters were applied during the search and only those articles were included in the study who is describing the duplication of ureter in the cadaveric dissection.

\section{Selecting Criteria}

The original research articles as well as case reports describing the duplication of ureter in the cadaveric dissection were included in the study. These articles should be published in English language from January 2011 to May 2020 time period. Articles published before January 2011 as well as articles published in other languages were not included in the present study. Studies containing radiological data as well as intraoperative data were not included in the present study. Animal based studies were also not included in the present study.

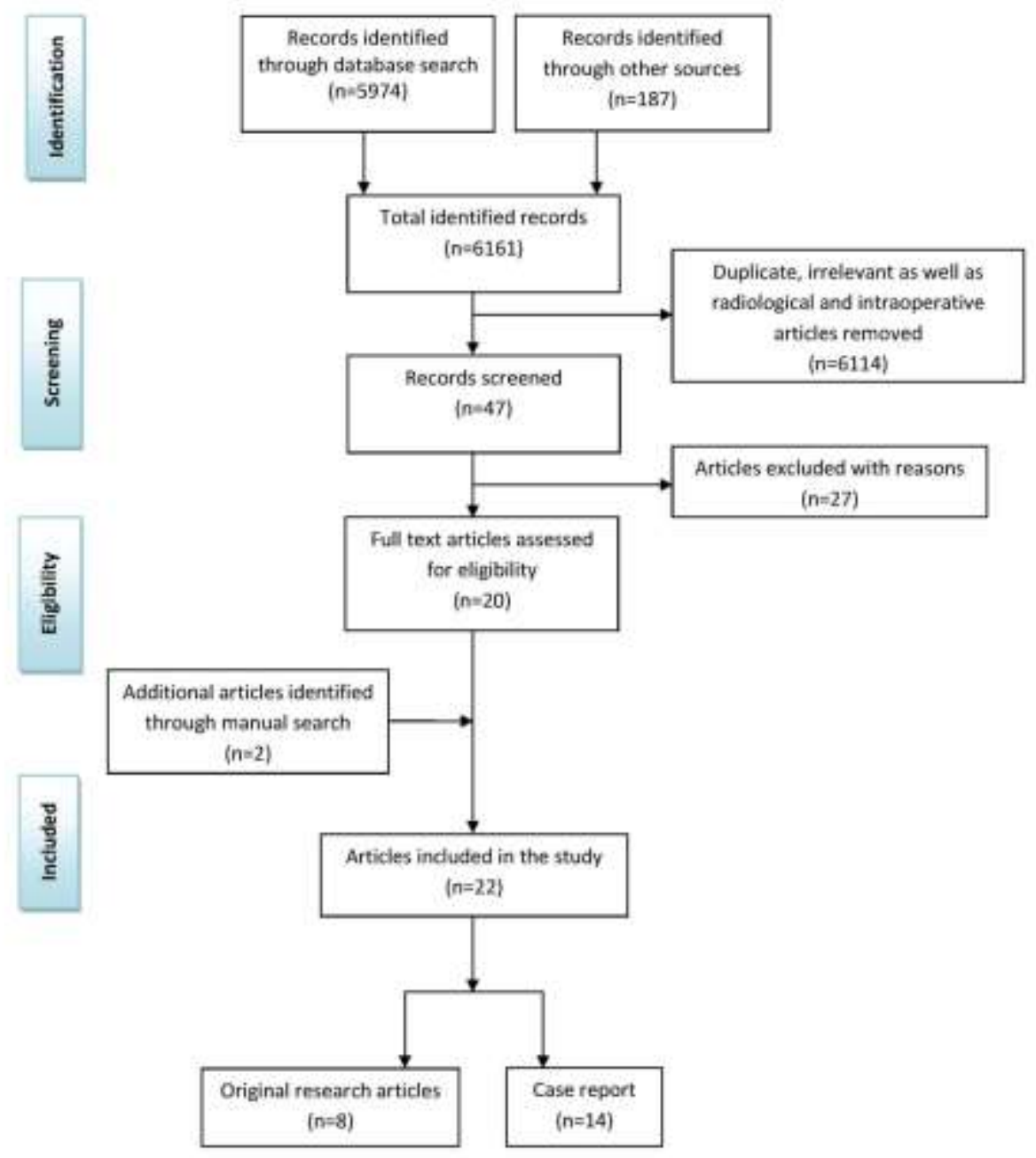

Fig-1: PRISMA flow chart showing the methodology of literature search

\section{RESULTS}

Initially 6161 articles were identified through various database searches as well as through other resources. After removal of radiological and intraoperative articles as well as removal of duplicate and irrelevant articles only 47 articles were screened. Out of 47 articles screened, 27 articles were excluded with valid reasons. 2 additional articles were identified through manual search. Ultimately total 22 articles were included in the present study, out of them 8 are original research articles and 14 are case reports. For each of the articles included in the study, year and type of publication, number of cadavers dissected, age and sex of cadaver, complete or incomplete duplication of ureter and unilateral or bilateral duplication of ureter were noted down.

\section{DISCUSSION}

Duplication of ureter is due to abnormalities in the branching pattern of ureteric bud. In complete duplication of ureter, both the ureters separately open in the urinary bladder, while in incomplete duplication of ureter, duplicated ureters unite at a variable distance away from the kidney and only one ureteric orifice is seen in the urinary bladder [11]. Dinanath $\mathrm{P}$ et al., found bilateral complete duplication of ureter in 40 year 
female cadaver. Both the ureters were seen to be opening in the urinary bladder separately. Upper ureter was opening at a lower level than the lower ureter which was at a higher level. The course and openings of ureters on both the sides were same. They found smaller left kidney and lobulated left kidney [12]. Morrow RM et al., found bilateral complete duplication of ureter in 40 year male cadaver. They also found a bilateral lower polar accessory renal arteries and a right accessory renal vein in the same cadaver. The lower polar accessory renal artery arises from abdominal aorta, while right accessory renal vein drain into inferior vena cava [13]. Prakash et al., dissected 50 cadavers and examined for the duplication of ureter. They found incomplete right ureteric duplication in 56 year old male cadaver. They also found incomplete left and complete right ureteric duplication in 43 year old male cadaver. In remaining 48 cadavers single ureters were present on both right and left side [14]. Kulkarni $\mathrm{V}$ et al., found bilateral incomplete duplication of upper ureter in 58 year male cadaver. Duplicated ureters rejoined opposite to ureteropelvic junction $7 \mathrm{~cm}$ distal to the renal hilum and continue downward as single ureter. They found contracted and granular right kidney. On each side, they found accessory renal artery, branches from abdominal aorta, supplying inferior pole of corresponding side of kidneys [15]. Pfoze $\mathrm{K}$ et al., found incomplete duplication of left ureter in 50 year male cadaver. Apart from incomplete duplication of left ureter, they didn't find any associated abnormality in urinary system [16].

Vaidya YP et al., found incomplete duplication of left ureter in 43 year old male cadaver. Duplicated ureters were running parallel to each other, with laterally situated ureter starting from the lower part of renal pelvis and medially situated ureter starting from the upper part of renal pelvis. Two segments of ureter descended separately in the abdomen in their whole course and enter into pelvis. Both the segments join with each other about $5 \mathrm{~cm}$ away from the urinary bladder. No other gross abnormalities were detected in the genitourinary system [17]. Dorko et al., studied congenital malformations of the ureter by dissecting 30 cadavers; 18 male and 12 female. They found incomplete left ureteric duplication in two cadavers; one in 59 year old male cadaver and one in 66 year old female cadaver. In 59 year old male cadaver, they found complete duplication of the renal pelvis also [18]. Kothandaraman U et al., dissected and observed 100 kidneys for the duplication of ureter. They found incomplete right ureteric duplication in one kidney out of total 100 studied. They observed inferior segmental artery, branch of abdominal aorta, as inferior aberrant artery which crosses the duplicated ureter from the posterior side.[19] Kumar V et al., found a case of incomplete left ureteric duplication with duplicated left renal pelvis also. Duplicated ureters fused at the level of pelvic brim to form the single ureter which opens into left lateral angle of the base of urinary bladder. Total length of ureter including renal pelvis was $25 \mathrm{~cm}$ and length of duplicated region was $17 \mathrm{~cm}$ [20]. Mousumee $S$ et al., dissected 15 adults and 65 perinatal cadavers to find anatomical and developmental variations of ureter. They found right complete ureteric duplication in one perinatal female cadaver and left incomplete ureteric duplication in another perinatal female cadaver. None of the 15 adult cadavers were having any ureteric duplication [21]. Abidu-Figueiredo $\mathrm{M}$ et al., found bilateral incomplete duplication of ureter in male cadaver. Both the ureters were having regular trajectories after fusion and enter the urinary bladder [22].

Deka B et al., dissected 30 formalin fixed human cadavers to study the cadaveric variations. In one cadaver they found incomplete bilateral duplication of ureter. In one cadaver they found right complete ureteric duplication and in another cadaver left complete ureteric duplication [23]. Ojha $\mathrm{P}$ et al., found incomplete right ureteric duplication in adult male cadaver. At the hilum of this right kidney two renal veins were seen as anterior most structure. These renal veins unite to form single vein just before entering into inferior vena cava. A single right renal artery was entering into the lower pole of the right kidney instead of normal entry via hilum. Two ureters were present posterior to the renal veins [24]. Choudhary U et al., dissected 32 cadavers (20 male and 12 female) and tried to find anatomical variations of kidney and ureter. They found incomplete right ureteric duplication in one cadaver and incomplete left ureteric duplication in another cadaver. One cadaver was having bilateral and two cadavers were having left unilateral lobulated kidneys. One cadaver was having bilateral; one cadaver was having left unilateral and one cadaver was having right unilateral accessory renal artery [25]. Kumari C et $a l$, found incomplete left ureteric duplication in 63 years old female cadaver. In the same cadaver right kidney was situated at abnormal higher level as compared to left kidney. Each kidney was supplied by an accessory renal artery arising from the anterior surface of abdominal aorta. These accessory renal arteries enter into the corresponding side of kidney from its lower pole [26]. Nagpal $\mathrm{H}$ et al., found incomplete right ureteric duplication in 60 years old female cadaver. Upper limb of duplicated ureter was having $19.5 \mathrm{~cm}$ length and the lower ureter was having $17.5 \mathrm{~cm}$ length. Both the limbs unite just $3 \mathrm{~cm}$ above the urinary bladder and enter into the urinary bladder by a single orifice. There was no other associated congenital abnormalities of urinary system [27]. Roy M et al., dissected 156 cadavers (122 male and 34 female) and tried to find anatomical variations of ureter. They found left complete ureteric duplication in one cadaver. Remaining 155 cadavers were having single ureter on each side draining the kidney [28].

Kasat PA et al., dissected 90 cadavers to study the variations in the urogenital system. They found 
incomplete right ureteric duplication in one cadaver and incomplete left ureteric duplication in another cadaver. Three cadavers were having bilateral and six cadavers were having unilateral lobulated kidneys. Three cadavers were having bilateral hypoplastic kidneys. One cadaver was having bilateral and five cadavers having unilateral accessory renal artery. One cadaver was having ectopic kidney at the level of pelvic brim [29]. Sudikshya KC et al., reported a case of left ureteric duplication in female cadaver having 60-65 years of age. It was associated with bifurcated renal pelvis as well as left accessory renal artery. Right side renal pelvis as well as ureter was normal in structure [30]. Shakthi KR et al., found a case of right double ureter in male cadaver during routine educational dissection for undergraduate students. Out of these two ureters, one ureter draining lower pole of right kidney was opening in the trigone of urinary bladder from right side. While the ureter draining the upper pole of right kidney was opening into the prostatic urethra on right side [31]. Arumugam S et al., carefully examined 50 kidneys retrieved from the cadavers for the presence of double ureter and noted down the incidence and types of double ureter. They found incomplete duplication of ureter in two right kidneys and one left kidney. In all these three specimens, the two limbs of double ureter fused at different levels to form a single ureter and open into the urinary bladder [32]. Raviprasanna $\mathrm{KH}$ et al., found a case of complete right ureteric duplication in female cadaver. Ureter draining the upper part of right kidney was longer and arising from the upper part of hilum of right kidney. Another ureter was starting from the lower part of hilum of right kidney [33].

\section{CONCLUSION}

Ureteric duplication is the developmental abnormality affecting the genitourinary system. If we compile the data of all original research articles as well as case reports included in the present study, than the incidence of left incomplete ureteric duplication is higher as compared to incidence of right incomplete ureteric duplication. Chances of congenital variations of ureter should be kept in mind while doing any radiological interventional procedures, laparoscopic or open surgical procedures. Diagnosis of such congenital variations of ureter before these procedures will reduce the incidence of any intra operative or postoperative complications.

\section{REFERENCES}

1. Standring, S. (2005). Gray's Anatomy. 38th edition. Edinburgh, London: Churchill Livingston.

2. Campbell, M. F., \& Walsh P. C. (1992). Campbell's urology. Anomalies of the Upper Urinary Tract. Walsh, P. C., Retik, A. B., Vaughan, E. D. Jr., \& Wein, A. J (ed): WB Saunders, Philadelphia.

3. Standring, S. (2008). Gray's Anatomy. 40th edition. Edinburgh, London: Churchill Livingston.
4. Chou, C. T., Yang, A. D., Hong, Y. C., \& Wu, H. K. (2006). Bilateral retrocaval ureters with IVC duplication. Abdom Imaging, 31:596-597.

5. Amitai, M., Hertz, M., Jonas, P., Apter, S., \& Heyman, Z. (1992). Ectopic ureterocele in adults with a comparison of the anomaly in children. Urol Radiol, 13:181-186.

6. Cronan, J. J., Amis, E. S., Zeman, R. K., \& Dorfman, G. S. (1986). Obstruction of the upper- pole moiety in renal duplication in adults: CT evaluation. Radiology. 161:17-21.

7. Varlatzidou, A., Zarokosta, M., Nikou, E., Theodoropoulos, P., Kakaviatos, D., Piperos, T., ... \& Mariolis-Sapsakos, T. (2018). Complete unilateral ureteral duplication encountered during intersphincteric resection for low rectal cancer. Journal of surgical case reports, 2018(10), rjy266.

8. Bergman, R. (1988). Compendium of Human Anatomic Variation: Text, Atlas, and World Literature .Urban \& Schwarzenberg, Baltimore.

9. Sadler, T. W. (2010). Urogenital system. In: Lanhman's Medical embryology, editor. 11th Ed. New Delhi: Lippincort William and Wilkins Publisher.

10. Moher, D., Liberati, A., Tetzlaff, J., \& Altman, D. G. (2009). Guidelines and guidance preferred reporting items for systematic reviews and metaanalyses: the PRISMA statement. PLoS Med. 6:e1000097.

11. Siomou, E., Papadopoulou, F., Kollios, K., Photopoulos, A., Evagelidou, E., Androulakakis, P., \& Siamopoulou, A. (2006). Duplex collecting system diagnosed during the first 6 years of life after a first urinary tract infection: a study of 63 children. J Urol. 175:678-682.

12. Dinanath, P., Ashwini, A., Annarao G., \& Nagaraj, S. (2011). Bilateral complete duplex renal pelves and ureters- a case report. Int J Anat Var. 4:192-194.

13. Morrow, R. M., Lufukuja, G. J., \& Fabian, F. M. (2011). Bilateral double ureters and accessory renal vessels in a Tanzanian male cadaver: a rare urinary system variation. Int J Anat Var. 4:184-8.

14. Prakash., Rajini, T., Venkatiah, J., Bhardwaj, A. K., Singh, D. K., \& Singh, G. (2011). Double ureter and duplex system- A cadaver and radiological study. Urol J. 8,145-158.

15. Kulkarni, V., Ramesh, B. R., \& Prakash, B. S. (2012). Bilateral bifid ureter with accessory renal artery: a case report. IJBMS. 3(3):67-70.

16. Pfoze, K., Thounaojam, K., \& Begendro, N. (2013). Unilateral incomplete double ureter. JEMDS. 2(15):2478-2479.

17. Vaidya, Y. P., Waghmare, J. E., Tarnekar, A. M., \& Shende, M. R. (2014). Unilateral isolated incompletely duplicated ureter. JMGIMS. 19(2):148-150. 
18. Dorko, F., Tokarcis, J., \& Vyborna, E. (2016). Congenital malformations of the ureter: anatomical studies. Anat Sci Int. 91(3):290-294.

19. Kothandaraman, U., \& Lokanadham, S. (2015). Unilateral partial duplication of ureter - congenital anomaly. Cukurova Medical Journal. 40(1):18-21.

20. Kumar, V., \& Remya, V. (2015). Unilateral incomplete bifid ureter: a case report. $J$ Morphol Sci. 32(3):203-205.

21. Mousumee, S., Santosh, S., Jyotirekha, G., Das, T. K., \& Baruah, A. (2015). Int J Dent Health Sci. 2(2):273-82.

22. Abidu-Figueiredo, M., Barbuto, N. S., Pires, L. A. S., \& Babinski, M. A. (2016). Bilateral bifid ureter: case report and clinical discussion. Int $J$ Med Health Res. 2(10):12-14.

23. Deka, B., \& Saikia, R. (2016). A study of human cadaveric ureter by simple dissection method. Int J Anat Res. 4(4):3005-3008.

24. Ojha, P., \& Prakash, S. (2016). Unilateral incomplete duplicated ureter - a clinical and embryological insight. Int J Med Res Health Sci. 5(8):68-70.

25. Choudhary, U., Kumar, S., Jee, K., Singh, A., \& Bharti, P. (2017). A cadaveric study on anatomical variations of kidney and ureter in India. Int $J$ Res Med Sci. 5(6):2358-2361.

26. Kumari, C., Motwani, R., Jhajhria, S. K., Rani, R., Jain, P., \& Raza, K. (2017).Higher right kidney and partial duplication of left ureter. Int J Anat Res. 5(2):3788-90.
27. Nagpal, H., \& Chauhan, R. (2017). Unilateral duplex collecting system with incomplete duplication of ureter - a case report. Int J Res Med Sci. 5(5):2254-2256.

28. Roy, M., Singh, B. R., Gajbe, U. L., \& Thute, P. (2017). Anatomical variations of ureter in central India: A cadaveric study. J Datta Meghe Inst Med Sci Univ. 12:277-279.

29. Kasat, P. A., Bhosale, Y. J., \& Muthiyan, G. (2018). A cadaveric study of variations in the urological system. Int J Anat Res. 6(3.3):5686-94.

30. Sudikshya, K. C., \& Babu, R. S. (2018). Unilateral bifurcated renal pelvis with partial duplication of ureter and an accessory renal artery: a case report. An Official Journal of NMC, Birgunj, Nepal. 3(1):91-94.

31. Shakthi, K. R., \& Chitra, R. (2019). Duplex collecting system of a right kidney with an ectopic ureter-a case report. Surg Med Open Acc J. 3(1):12.

32. Arumugam, S., Subbiah, N., \& Mariappan, S. A. (2020). Double Ureter: Incidence, Types, and Its Applied Significance-A Cadaveric Study. Cureus. 12(4):e7760.

33. Raviprasanna, K. H., \& Vinay, G. (2020). Complete Unilateral Ureteral Duplication Encountered during Cadaveric Dissection and its Embryological Basis - A Case Report. EC Clinical and Experimental Anatomy. 3(3):1-5. 